С.А. Макаров ${ }^{1}$, С.П. Бєляк ${ }^{2}$, О.В. Висоцький ${ }^{1}$

${ }^{1}$ Харківський національний університет Повітряних Сил ім. І. Кожедуба, Харків

${ }^{2}$ Військова частина АЗ297, Дніпро

\title{
ОЦІНКА СТІЙКОСТІ СИСТЕМИ ЗВ'ЯЗКУ ТА РАДІОТЕХНІЧНОГО ЗАБЕЗПЕЧЕННЯ
}

У роботі проводиться аналіз кількісних показників стійкості системи зв'язку та радіотехнічного забезпечення. Обгрунтовуються шляхи підвищення завадостійкості системи зв'язку та радіотехнічного забезпечення за рахунок покращеення енергетичної, структурної та інформаційної скритності сигналів радіоелектронних засобів системи при використанні шумоподібних хаотичних сигналів. Визначено показники стійкості системи зв'язку та радіотехнічного забезпечення: живучості, надійності та завадостійкості. Розроблено організаційно-технічні заходи забезпечення стійкості системи зв'язку та радіотехнічного забезпечення.

Ключові слова: стійкість, система зв'язку та радіотехнічного забезпечення, скритність, шумоподібний сигнал, хаотичний сигнал.

\section{Вступ}

Постановка проблеми. Виходячи 3 аналізу досвіду ведення операцій (бойових дій) у зоні проведення ООС на сході України та досвіду інформаційного забезпечення сучасних збройних конфліктів, вимоги до стійкості системи зв'язку та радіотехнічного забезпечення (РТ3) суттєво зростають [1].

Основною метою дослідження є аналіз основних складових стійкості системи зв'язку та РТЗ, що дозволить визначити напрямки іiі підвищення для забезпечення спроможності виконувати завдання управління за умов різких змін обстановки та впливу противника вогневими і радіоелектронними засобами, диверсійно-розвідувальними групами, повітряних десантів на об'єкти системи управління та PT3.

Аналіз останніх досліджень і публікацій. Оцінка ефективності системи зв'язку та РТЗ за всіма (показниками) властивостями вимагає великих витрат часу та характеризується складністю розрахунків [2-6]. Тому на практиці, особливо в умовах обмеженого часу на прийняття рішення, людських та матеріальних ресурсів, оцінку ефективності системи зв'язку та РТЗ здійснюють за одним або кількома показниками.

У [2] розроблено методику оцінки стійкості системи військового зв'язку за умов прийняття обмежень щодо надійності та завадостійкості системи. Кількісними показниками, що характеризують стійкість системи зв'язку в [6], взяті коефіцієнт справної дії і середній час справної роботи. У [5] розглядається підхід до вибору та оцінки показників ефективності системи зв'язку та РТЗ польотів авіації, які характеризують якість інформаційного забезпечення.
Враховуючи досвід проведення АТО та особливостей проведення ООС [1] пропонується в якості базового показника оцінки якості системи зв'язку та РТ3 використовувати ії стійкість. Тому актуальним $€$ дослідження стійкості системи зв'язку та РТЗ та шляхів ії підвищення.

\section{Виклад основного матеріалу}

Система зв'язку та радіотехнічного забезпечення польотів - це система забезпечення процесів обміну інформацією і іiі обробки, здобування інформації про повітряну обстановку і видачі iї на пункти управління, забезпечення екіпажів повітряних суден інформацією, що необхідна їм для зльоту, визначення свого місця у повітряному просторі, виходу в заданий район або район аеродрому, заходу на посадку і посадки, а також вирішення інформаційних, розрахункових і інших задач, та контролю за їх виконанням із застосуванням засобів та комплексів зв'язку та радіотехнічного забезпечення польотів в системі управління Повітряними Силами.

До системи зв'язку та РТЗ висуваються такі вимоги: постійна готовність до забезпечення управління військами (силами), стійкість, мобільність, пропускна спроможність та розвідзахищеність, виконання яких визначає якість системи зв'язку та PT3 [7].

Стійкість системи зв'язку та РТЗ визначає властивість системи зберігати працездатність та забезпечувати інформаційний процес в системі управління в умовах впливу різноманітних факторів.

Стійкість системи зв'язку та РТЗ (СЗРТЗ) визначається живучістю, надійністю, завадостійкістю засобів зв'язку та РТ3 [6-7]. 
Живучість системи зв'язку та РТЗ визначає здатність системи виконувати завдання за призначенням в умовах застосування противником засобів ураження. Показником живучості слід вважати ймовірнісну величину $K_{\text {жив }}$, яка визначається ймовірністю вогневого ураження засобів зв'язку та РТЗ $P_{\text {вогн }}$ :

$$
K_{\text {жив }}=1-P_{\text {вогн }}
$$

Живучість ССРТЗ визначається живучісю іiі складових частин, які при вогневому ураженні змінюють свій стан відповідно до типу ураження.

Надійність системи зв'язку та РТЗ обумовлює здатність системи зв'язку та РТЗ виконувати завдання за призначенням, зберігаючи в часі показники у межах, передбачених експлуатаційною документацією на засоби зв'язку та РТЗ.

Основними кількісними показниками надійності засобів зв'язку та РТЗ слід вважати такі:

- коефіцієнт справної дії засобів зв'язку та РТЗ $\kappa_{n p}$, який визначає ймовірність працездатності засобів у будь-який момент часу $P_{n p}$;

- коефіцієнт простою (непрацездатності) засобів зв'язку та РТЗ $\kappa_{\text {непр }}=1-\kappa_{\text {cnp }}$, який визначає ймовірність непрацездатність засобів у будь-який момент часу $P_{\text {неnр }}$;

- середній час працездатної роботи засобів зв'язку та РТЗ $T_{n p}$;

- середній час простою (непрацездатної роботи) засобів зв'язку та РТЗ $T_{\text {непр }}$, які пов'язані співвідношенням

$$
\kappa_{n p}=\frac{T_{n p}}{T_{n p}+T_{\text {неnp }}}=\frac{\sum_{i=1}^{n} t_{n p_{i}}}{\sum_{i=1}^{n} t_{n p_{i}}+\sum_{i=1}^{n} t_{\text {непр }}},
$$

де $t_{n p_{i}}$ i $t_{\text {непр }}$ - час працездатної та непрацездатної роботи засобів зв'язку та РТЗ протягом $i$-го інтервалу роботи;

$n$ - число інтервалів роботи протягом визначеного часу (доби, неділі, місяця тощо).

Показник надійності СЗРТЗ можливо виразити через ймовірність безвідмовної роботи засобів

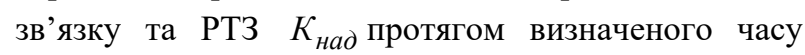
$t_{\text {визн }}$ за відомого часу безвідмовної роботи засобів зв’язку та РТЗ $T_{б . p .}$ :

$$
K_{\text {над }}=e^{-\frac{t_{\text {визн }}}{T_{\text {б.p. }}}} .
$$

Завадостійкість системи зв'язку та РТЗ визначає здатність системи функціонувати (виконувати завдання за призначенням) 3 визначеною якістю зв’язку та РТЗ в умовах дії випадкових та навмисних радіозавад. Показником завадостійкості слід вважати ймовірнісну величину $K_{3 . c m}$, яка визначається ймовірностями подавлення каналів зв'язку та засобів РТЗ навмисними $\left(P_{\text {н.з. }}\right)$ та випадковими $\left(P_{\text {в.з. }}\right)$ та ймовірністю невиконання умов електромагнітної сумісності електромагнітної сумісності $\left(P_{\text {н.емс }}\right)$ :

$$
K_{\text {з.сm }}=\left(1-P_{\text {н.з. }}\right)\left(1-P_{\text {в.з. }}\right)\left(1-P_{\text {н.емс }}\right) .
$$

Таким чином, показником стійкості СЗРТЗ слід вважати ймовірнісну величину $K_{c m}$ СзРТ3, яка визначається ймовірностями $K_{\text {жив }}, K_{\text {над }}$ та $K_{\text {з.ст }}$ :

$$
K_{\text {ст СзРТз }}=1-\left(1-K_{\text {жив }}\right)\left(1-K_{\text {над }}\right)\left(1-K_{3 . \mathrm{cm}}\right) .
$$

Стійкість системи зв'язку та РТЗ досягається (рис. 1) [7]:

- створенням розгалуженої структури системи зв'язку та РТЗ на основі комплексного використання різних засобів, комплексів зв'язку та засобів РТЗ $\left(K_{\text {жив }}, K_{3 . \mathrm{cm}}\right)$;

- визначенням основних, резервних та дублюючих засобів (комплексів) зв'язку та РТЗ ( $\left.\kappa_{\text {над }}\right)$;

- рознесенням на місцевості ліній зв'язку, створенням обхідних каналів і трактів зв'язку пунктів управління ( $\left.K_{\text {жив }}\right)$;

- розосередженням елементів інформаційнотелекомунікаційних вузлів (ITB) пунктів управління та винесенням за їх межі незадіяних сил і засобів, а також випромінювальних засобів ( $\left.K_{\text {жив }}, K_{\text {над }}\right)$;

- плануванням і проведенням заходів для захисту системи зв'язку та РТЗ від усіх видів розвідки, впливу вражаючих факторів зброї та засобів радіоелектронної боротьби противника $\left(K_{3 . \mathrm{cm}}\right)$;

- застосування технічних методів забезпечення розвідзахищеності системи зв'язку та РТЗ $\left(K_{3 . \mathrm{cm}}\right)$;

- навченістю обслуговуючого персоналу до забезпечення зв'язку, РТЗ і АУВ в умовах впливу всіх вражаючих факторів та знанням способів захисту від них $\left(K_{\text {жив }}\right)$;

- розташуванням випромінювальних засобів зв'язку (радіо-, супутникових, радіорелейних, тропосферних) та РТЗ на обмеженій території з урахуванням норм частотно-територіального рознесення $\left(K_{\text {жив }}, P_{\text {з.ст }}\right)$;

- створенням, використанням і вчасним відновленням резервів сил та засобів, комплексів зв'язку та засобів систем РТЗ $\left(K_{\text {над }}\right)$;

- здійсненням оперативного маневру силами та засобами, комплексами зв'язку та засобами РТЗ, каналами передавання і трактами зв'язку $\left(K_{\text {жив }}\right)$; 
- наявністю аварійно-відновлювальних команд 3 ліквідації наслідків застосування противником засобів ураження та вмілою організацією їх роботи $\left(K_{\text {над }}\right)$;

- своєчасним проведенням технічного забезпечення засобів ССРТЗ ( $\left.K_{\text {над }}\right)$;

- охороною та обороною ITВ, опорних В3, станцій і ліній зв'язку та засобів РТЗ ( $\left.K_{\text {жив }}\right)$.

За умови прийнятого обмеження щодо живучості $\left(K_{\text {жив }}=1\right)$ та надійності $\left(K_{\text {над }}=1\right)$ стійкість системи зв'язку та РТЗ визначається їі завадостійкістю:

$$
K_{c m \text { С } 3 Р T 3}=1-K_{3 . \mathrm{cm}} .
$$

Здатність засобів зв'язку та РТЗ протистояти мірам радіотехнічної розвідки, спрямованим на виявлення факту їх роботи та визначення необхідних для радіопротидії параметрів сигналу, визначає скритність як характеристику завадозахищеності безпосередньо засобів зв'язку та РТЗ та СЗ3Р3 в цілому.

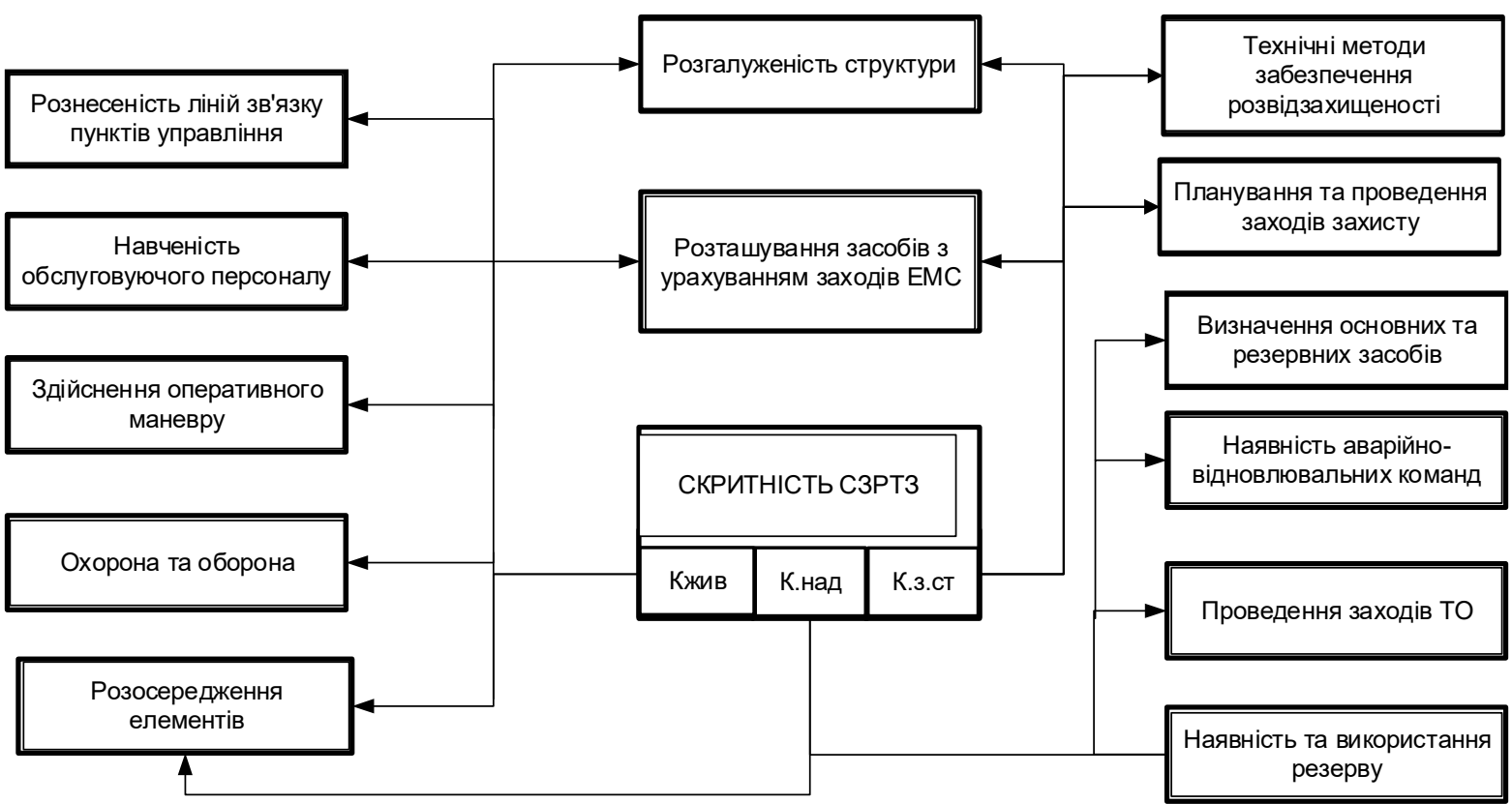

Рис. 1. Організаційно-технічні заходи забезпечення стійкості ССРТЗ

Висока скритність СЗРТЗ дозволяє уникнути постановки прицільних завад, перешкоджає розкриттю позиційних районів, знижує ймовірність перехоплення інформації засобами радіоелектронної розвідки та відповідно зменшує ймовірність подавлення каналів зв'язку та засобів РТ3 навмисними радіозавадами $P_{н . з .}$. Відповідно до виразу (4) зменшення $P_{H .3 .}$ призводить до покращення показників

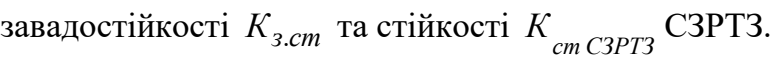

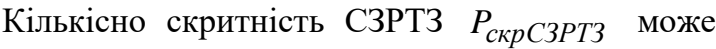
бути визначено ймовірністю розвідки функціонування СЗРТЗ $P_{p \text { СзРТз }}$ :

$$
P_{\text {скр С } Р \text { Рз }}=1-P_{p С 3 Р Т 3} \text {. }
$$

Якщо противник не розвідає параметри радіоліній СЗРТЗ, то очевидна постановка тільки шумової загороджувальної завади. Якщо параметри радіолінії в процесі розвідки противником визначені, то найімовірніше постановка прицільної завади. Радіорозвідка, як правило, припускає послідовне виконання трьох основних завдань: виявлення факту роботи радіоелектронних засобів (РЕЗ) (виявлення сигналу), визначення структури виявленого сигналу (на основі визначення ряду його параметрів) і розкриття змісту інформації, що передається. Останнє завдання іноді має самостійне значення (є однієї 3 кінцевих цілей). У загальному випадку розкриття змісту переданої інформації дозволяє організувати більше ефективне радіоподавлення.

Перерахованим завданням радіорозвідки можуть бути протиставлені три види скритності РЕ3 зв'язку та РТЗ: енергетична, структурна й інформаційна.

Енергетична скритність РЕЗ характеризує здатність протистояти мірам, спрямованим на виявлення сигналу розвідувальним прийомним пристроєм. Для забезпечення енергетичної скритності необхідний вибір такої потужності випромінювання передавача й такого спектра випромінювання, при яких потужність сигналу на вході розвідувального приймача була б менше його реальної чутливості.

Для забезпечення енергетичної скритності можливе використання широкосмугових сигналів, 
оскільки при малій спектральній щільності й за умови щодо вузької смуги пропущення розвідувального приймача енергія прийнятого сигналу, що розвідується, буде невелика [8; 10].

Виявлення сигналу розвідувальним приймачем відбувається в умовах дії завад (шумів), і може супроводжуватися помилками двох видів: пропуск сигналу при його наявності на вході й помилкове виявлення (хибна тривога) за відсутності сигналу. Ці помилки носять імовірнісний характер. Кількісною мірою енергетичної скритності $i$-го РЕ3 СЗРТЗ може бути ймовірність правильного виявлення

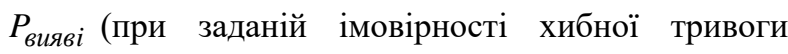
$\left.P_{x m i}\right)$, які у свою чергу залежать від відношення сигнал-завада в радіолінії й правила прийняття рішення щодо виявлення сигналу.

Структурна скритність характеризує здатність РЕ3 протистояти мірам радіорозвідки, спрямованим на розкриття сигналу [9; 10]. Це означає розпізнавання форми сигналу, обумовленої способами його кодування й модуляції, тобто ототожнення виявленого сигналу з одним 3 безлічі апріорно відомих сигналів.

Структурна скритність забезпечується використанням сигналів, складна структура яких утрудняє їхню розвідку противником. В якості таких сигналів можуть використовуватися сигнали на основі псевдовипадкових послідовностей великої тривалості, сигнали зі складною модуляцією й т.п. Використання складних сигналів висуває особливі вимоги до системи за точністю синхронізації приймальної та передавальної сторін.

Для збільшення структурної скритності необхідно мати як можливо більший ансамбль використовуваних сигналів і досить часто змінювати форму сигналів.

Завдання визначення структури сигналу є статистичної мірою структурної скритності, а її кількісною мірою може служити ймовірність розкриття структури сигналу $i$-го РЕЗ СЗРТЗ $P_{\text {cmpi }}$ за умови, що сигнал виявлений. Таким чином, $P_{c m p i} €$ умовною ймовірністю.

Інформаційна скритність визначається здатністю протистояти мірам, спрямованим на розкриття змісту переданої за допомогою сигналів інформації. Розкриття змісту переданої інформації означає ототожнення кожного прийнятого сигналу або їхньої сукупності з тим повідомленням, що передається. Це завдання вирішується з'ясуванням ряду ознак сигналу, наприклад, місця даного сигналу в безлічі прийнятих, частоти його появи, зв'язку факторів появи того або іншого сигналу зі зміною стану керованого об'єкта й т.д.

Наявність апріорної й апостеріорної невизначеностей робить це завдання імовірнісним. В якості кількісної міри інформаційної скритності $i$-го РЕ3 СЗРТЗ приймають імовірність розкриття змісту переданої інформації $P_{i н \phi i}$ за умови, що сигнал виявлений і виділений (тобто структура його розкрита). При цьому $P_{i н ф i}$ також $є$ умовною ймовірністю.

Таким чином, скритність СЗРТЗ $P_{\text {скрСзРТЗ }}$ враховує енергетичну, структурну й інформаційну скритність сигналу $i$-го РЕЗ СЗРТЗ та визначається співвідношенням:

$$
P_{\text {скр СзРТз }}=1-\prod_{i} P_{\text {вияві }} P_{\text {стрі }} P_{\text {інфі }} .
$$

Одним із шляхів підвищення енергетичної скритності [9] є збільшення ширини спектра використовуваних сигналів, що досягається не тільки застосуванням ШСС, але й шумоподібними сигналами. Маючи ознаки випадкових шумових сигналів (широкий спектр, що міняється по зовнішньому вигляді при кожній вибірці реалізація) шумоподібні й хаотичні сигнали мають головну властивість, що відрізняє їх від звичайних шумів: вони реалізуються 3 використанням розробленого математичного алгоритму.

Іншими словами вони мають властивість відтворюваності, тобто можуть бути точно відтворені стільки разів, скільки це буде потрібно для застосування.

Альтернативне рішення проблеми дає застосування шумоподібних хаотичних сигналів (ШХС), формованих нелінійними системами 3 динамічним хаосом [8-12]. Шумоподібність і самосинхронізуємість систем, заснованих на хаосі, дають їм потенційні переваги й над традиційними системами з розширенням спектра. Маючи кореляційні властивості не гірше, ніж у М-послідовностей, ШХС мають практично необмежений набір довжин, можуть утворювати ансамблі сигналів більших обсягів і $є$ нелінійними, що утрудняє їхнє розпізнавання $з$ метою наступного відтворення.

Наявність безлічі корисних властивостей нелінійних динамічних систем, що демонструють хаотичне поводження, дозволяє розробити велику кількість різноманітних підходів до рішення проблеми підвищення скритності РЕЗ СЗРТЗ.

Зокрема, до таких властивостей можна віднести:

- чутливість до початкових умов (експоненційне розбігання траєкторій), часто вимірюється показником Ляпунова;

- зростаюча складність поводження динамічної системи в міру зміни деякого іiї параметра, можливість одержання великої кількості хаотичних мод в одному джерелі хаосу;

- можливість керування хаотичними режимами шляхом малих змін параметрів нелінійної системи; 
- можливість одержання складних хаотичних станів у простих за структурою пристроях;

- постійну ентропію (інформацію) хаотичного сигналу на відлік (в одиницю часу). Інформаційний стан визначається тільки динамічними властивостями джерела хаосу й не пов'язаний з точністю виміру, не збільшується при розширенні смуги частот;

- широка суцільна смуга частот, як наслідок у них може бути "вкладена" велика кількість інформації без зміни спектральних і інших фізичних властивостей.

- наявність великої кількості методів модуляції-демодуляції хаотичного процесу інформаційним повідомленням;

- явище хаотичної синхронізації;

- неможливість розрізнення випадкових і хаотичних процесів з використанням традиційних підходів (вивчення статистичних, спектральних, кореляційних властивостей).

\section{Висновки}

Підвищення енергетичної, структурної та інформаційної скритності сигналів радіоелектронних засобів зв'язку та радіотехнічного забезпечення польотів авіації за рахунок застосування не тільки шумоподібних сигналів, а й хаотичних процесів та послідовностей з властивостями, близькими до білого шуму, формованих нелінійними системами 3 динамічним хаосом, обумовлює підвищення здатності PE3 функціонувати 3 визначеною якістю в умовах дії випадкових та навмисних радіозавад. Властивості нелінійних динамічних систем, що демонструють хаотичне поводження, дозволяють застосувати велику кількість різноманітних підходів до вирішення проблеми підвищення скритності РЕЗ СЗРТЗ та стійкості забезпечення інформаційного процесу в системі зв'язку та радіотехнічного забезпечення. Мета досліджень досягнута.

\section{Список літератури}

1. Застосування досвіду АТО та особливостей проведення ООС для підготовки фахівців зв'язку, РТЗ, А та IC / К.С. Васюта, О.М. Чекунова, С.А. Макаров та ін. - Х.: ХНУПС, 2018. - 292 с.

2. Методика оцінки стійкості системи військового зв'язку / М.О. Масесов, І.О. Бондаренко, О.І. Садиков, В.І. Макарчук // Збірник наукових праць Військового інституту телекомунікацій та інформатизації. - 2016. - № 1. - С. 94-102.

3. Боговик А.В. Эффективность системы военной связи и методы ее оценки / А.В. Боговик, В.В. Игнатов. - СПб: Военная академия связи, 2006. -183 с.

4. Юхновський С.А. Часткова методика оцінки відповідності системи зв'язку потребам визначеної системи управління протиповітряною обороною / С.А. Юхновський, О.П. Кулик, І.Л. Костенко // Наука і техніка Повітряних Сил Збройних Сил України. - 2017. - № 2(27). - С. 124-126.

5. Ивануткин А.Г. Подход к выбору показателей эффективности связи и радиотехнического обеспечения полетов авиации [Електронний ресурс] / А.Г. Ивануткин, М.А. Данилин, М.Ю. Пресняков // Труды МАИ. - 2016. - № 86. - Режим доступу: https://docplayer.ru/27884857-Podhod-k-vyboru-pokazateley-effektivnosti-svyazi-i-radiotehnicheskogoobespecheniya-poletov-aviacii.html.

6. Офіціальний сайт STUDFILE.NET. Основи організації військового зв'язку [Електронний ресурс]. - Режим доступу: https://studfile.net/preview/3740879/page:22/.

7. Організація військового зв'язку / В.Г. Шолудько, М.Ю. Єсаулов, О.В. Вакуленко, Т.Г. Гурський, М.М. Фомін. K.: BITI, 2017 p. -282 c.

8. Аналіз IID-скритності безперервних хаотичних сигналів / П.Ю. Костенко, В.В. Слободянюк, С.В. Волинець, М.Л. Крючка // Системи обробки інформації. - 2018. - № 1. - С. 20-26.

9. Kostenko P.Yu. Stealthiness of analytical chaotic signals / P.Yu. Kostenko, V.V. Slobodyanuk, A.N. Barsukov // Radioelectronics and Communications Systems. - 2017. - № 5. - P. 132-140.

10. Кувшинов О.В. Оцінка структурної скритності широкосмугових сигналів / О.В. Кувшинов, Р.М. Вознюк // Збірник наукових праць ВІТІ НТУУ “КПІ”. - 2011. - № 1. - С. 106-111.

11. Повышение эффективности когерентной обработки хаотических сигналов при передаче бинарных сообщений с использованием суррогатных сигналов / П.Ю. Костенко, В.И. Василишин, С.Н.Симоненко, О.В. Висоцький, Д.С. Яковенко // Радиоэлектроника. - 2012. - № 7. - С. 24-33.

12. Оценка структурной скрытности хаотических сигналов / П.Ю. Костенко, С.Н.Симоненко, А.Н. Барсуков, А.В. Антонов // Радиоэлектроника. - 2012. - № 11. - С. 3-10.

\section{References}

1. Vasyuta, K.S., Chekunova, O.M. and Makarov, S.A. (2018), "Zastosuvannya dosvidu ATO ta osoblyvostey provedennya OOS dlya pidhotovky fakhivtsiv zvyazku, RTZ, A ta IS" [Application of ATO experience and peculiarities of conducting OOS for training of communication specialists, RTZ, A and IS], KhNUPS, Kharkiv, 292 p.

2. Masesov, M.O., Bondarenko, I.O., Sadikov, O.I. and Makarchuk, V.I. (2016), "Metodyka otsinky stiykosti systemy viys'kovoho zv"yazku" [Methodology for assessing the stability of the military communications system], Scientific Works of Military Institute of Telecommunications and Informatization, No. 1, pp. 94-102.

3. Bogovik, A.V. and Ignatov, V.V. (2006), "Effektivnost' sistemy voyennoy svyazi i metody yeye otsenki" [The effectiveness of the military communications system and methods for its assessment], MAC, SaintPetersburg, $183 \mathrm{p}$. 
4. Yukhnovsky, S.A., Kulik, O.P. and Kostenko, I.L. (2017), "Chastkova metodyka otsinky vidpovidnosti systemy zv"yazku potrebam vyznachenoyi systemy upravlinnya protypo-vitryanoyu oboronoy" [Partial methodology for assessing the compliance of a communications system to the needs of a particular anti-aircraft defense management system], Science and Technology, No. 2 (27), pp. 124-126.

5. Ivanutkin, A.G., Danilin, M.A. and Presnyakov, M.Yu. (2016), "Podkhod k vyboru pokazateley effektivnosti svyazi i radiotekhnicheskogo obespecheniya poletov aviatsii" [Approach to the selection of indicators of communication efficiency and radio-technical support for aviation flights], MAI Proceedings, No. 86, pp. 94-102, available at: www.docplayer.ru/27884857Podhod-k-vyboru-pokazateley-effektivnosti-svyazi-i-radiotehnicheskogo-obespecheniya-poletov-aviacii.html.

6. The official site of STUDFILE.NET (2015), "Osnovy orhanizatsii viiskovoho zv'iazku" [Fundamentals of Military Communication], available at: www.studfile.net/preview/3740879/page:22/.

7. Sholudko, V.G., Yesaulov, M.Yu., Vakulenko, O.V. and Gursky, T.G. (2017), "Orhanizatsiya viys'kovoho zv"yazku" [Organization of military communications], VITI, Kyiv, 282 p.

8. Kostenko, P.Yu., Slobodyanyuk, V.V. and Volynets, S.V. (2018), “Analiz IID-skrytnosti bezperervnykh khaotychnykh syhnaliv" [Analysis of IID-secretness of continuous chaotic signals], Information Processing Systems, No. 1, pp. 20-26.

9. Kostenko, P.Yu., Slobodyanuk, V.V. and Barsukov, A.N. (2017), Stealthiness of analytical chaotic signals, Radioelectronics and Communications Systems, No. 5, pp. 132-140.

10. Kuvshinov, O.V. and Wozniuk, R.M. (2011), "Otsinka strukturnoyi skrytnosti shyrokosmuhovykh syhnaliv" [Assessment of the structural latency of broadband signals], Scientific Works of Military Institute of Telecommunications and Informatization, No. 1, pp. 106-111.

11. Kostenko, P.Yu., Vasilyshyn, V.I., Simonenko, S.N., Vysotskyi, O.V. and Yakovenko, D.S. (2012), "Povysheniye effektivnosti kogerentnoy obrabotki khaoticheskikh signalov pri peredache binarnykh soobshcheniy s ispol'zo-vaniyem surrogatnykh signalov" [Improving the efficiency of coherent processing of chaotic signals in the transmission of binary messages using surrogate signals], Radio Electronics, No. 7, pp. 24-33.

12. Kostenko, P.Yu., Simonenko, S.N., Barsukov, A.N. and Antonov, A.V. (2012), "Otsenka strukturnoy skrytnosti khaoticheskikh signalov" [Assessment of structural secrecy of chaotic signals], Radio Electronics, No. 11, pp. 3-10.

Надійшла до редколегії 05.02.2020

Схвалена до друку 10.03.2020

\section{Відомості про авторів:}

\section{Макаров Сергій Анатолійович}

кандидат технічних наук доцент

начальник факультету

Харківського національного університету

Повітряних Сил ім. І. Кожедуба,

Харків, Україна

https://orcid.org/0000-0002-4708-5449

\section{Бєляк Сергій Павлович}

заступник командира полку,

Дніпро, Україна

https://orcid.org/0000-0002-7220-5975

\author{
Висоцький Олег Володимирович \\ кандидат технічних наук \\ доцент \\ доцент кафедри \\ Харківського національного університету \\ Повітряних Сил ім. І. Кожедуба, \\ Харків, Україна \\ https://orcid.org/0000-0001-5657-0529
}

\section{Information about the authors:}

\author{
Serhii Makarov \\ Candidate of Sciences Associate Professor \\ Head of the Faculty \\ of Ivan Kozhedub Kharkiv \\ National Air Force University, \\ Kharkiv, Ukraine \\ https://orcid.org/0000-0002-4708-5449
}

\author{
Serhii Belyak \\ Deputy Regiment Commander, \\ Dnipro, Ukraine \\ https://orcid.org/0000-0002-7220-5975
}

\author{
Oleg Vysotskyy \\ Candidate of Sciences \\ Associate Professor \\ Senior Lecturer \\ of Ivan Kozhedub Kharkiv \\ National Air Force University \\ Kharkiv, Ukraine \\ https://orcid.org/0000-0001-5657-0529
}

\title{
ОЦЕНКА СТОЙКОСТИ СИСТЕМИ СВЯЗИ И РАДИОТЕХНИЧЕСКОГО ОБЕСПЕЧЕНИЯ
}

\author{
С.А. Макаров, С.П. Беляк, О.В. Висоцкий
}

В работе проводится анализ количественных показателей устойчивости системы связи и радиотехнического обеспечения. Обосновываются пути повышения помехоустойчивости системы связи и радиотехнического обеспечения за счет улучшения энергетической, структурной и информационной скрытности сигналов радиоэлектронных средств системы при использовании шумоподобных хаотических сигналов. Определены показатели устойчивости системы связи и радиотехнического обеспечения: живучести, надежности и помехоустойчивости. Разработаны организацион- 
но-технические меры обеспечения устойчивости системы связи и радиотехнического обеспечения. Повышение энергетической, структурной и информационной скрытности сигналов радиоэлектронных средств связи и радиотехнического обеспечения полетов авиации за счет применения не только шумоподобных сигналов, но и хаотических процессов и последовательностей со свойствами, близкими к белому иуму, сформированных нелинейными системами с динамичным хаосом, обусловливает повышение способности РЭС функционировать с определенным качеством в условиях действия случайных и преднамеренных радиопомех. Свойства нелинейных динамических систем, демонстрируюших хаотическое поведение, позволяют применить большое количество разнообразных подходов к решению проблемы повыиения скрытности и устойчивости обеспечения информационного прочесса в системе связи и радиотехнического обеспечения.

Ключевые слова: устойчивость, система связи и радиотехнического обеспечения, скрытность, иумоподобньий сигнал, хаотический сигнал.

\section{EVALUATION OF THE SUSTAINABILITY OF THE COMMUNICATION SYSTEM AND RADIO-TECHNICAL SUPPLY}

S. Makarov, S. Belyak, O. Vysotsky

Based on the analysis of the experience of conducting operations (combat operations) in the area of the operation of the Joint Forces in the east of Ukraine and the experience of information support of modern armed conflicts, the requirements for the stability of the communication system and radio technical support are significantly increasing. The main purpose of the study is to analyze the main components of the stability of the communication system and radio technical support, which will determine the directions of its enhancement to ensure the ability to perform management tasks in the face of dramatic changes in the environment and the impact of the enemy by fire and electronic means, sabotage groups, airborne troops control and radio engineering. The paper analyzes the quantitative indicators of the stability of the communication system and radio-technical support. The ways of increasing the noise immunity of the communication system and the radio-technical support by improving the energy, structural and information secretiveness of the signals of the radio-electronic means of the system when using noiselike chaotic signals are substantiated. Indicators of stability of communication system and radio technical support are determined: survivability, reliability and noise immunity. Organizational and technical measures have been developed to ensure the sustainability of the communication system and radio technical support. Increasing the energy, structural and informational secrecy of signals of radio-electronic communication means and radio-technical support of aviation flights through the use of not only noise-like signals, but also chaotic processes and sequences with properties close to white noise formed by nonlinear systems with dynamic chaos, causes an increase in the ability to function with a certain quality in the case of accidental and deliberate radio interference.The properties of nonlinear dynamic systems exhibiting chaotic behavior allow us to apply a large number of different approaches to solving the problem of increasing the secrecy and stability of providing information process in the communication and radio engineering system.

Keywords: stability, communication and radio support system, stealth, noise signal, chaotic signal. 